\title{
Best project selection by using of group TOPSIS method
}

\begin{abstract}
Selecting projects is an important problem, yet often difficult task. It is complicated because there is usually more than one dimension for measuring the impact of each project and especially when there is more than one decision maker. This paper considers a real application of project selection for telecommunication projects with using the opinion of experts by one of the group decision making model, it is called TOPSIS method. Four kinds of criteria include qualitative, quantitative, negative and positive criteria have been considered for selecting the best one amongst five projects and ranking them. We have also used from three expert's opinion in cable network. Finally the introduced method is used in a case study (telecommunication sector) and extracted results from it are analyzed from different points of view.
\end{abstract}

Keyword: Project selection; Decision making; MCDM (multi criteria decision making); Group TOPSIS method 